\title{
ОБЩАЯ ХАРАКТЕРИСТИКА НАСЛЕДСТВЕННОГО ДОГОВОРА В ПРАВЕ ГЕРМАНИИ
}

\section{Шмакова Анастасия Сергеевна}

студент

\section{Чуракова Екатерина Николаевна}

к.ю.н., доцент

ФГФОУ ВО «Самарский государственный экономический университет»

Аннотация: Статья посвящена истории, изучению особенностей правового режима наследственного договора в гражданском праве в Германии. Авторы приходят к выводу, что данный институт носит смешанный, наследственно-правовой и договорно-правовой характер. В связи с этим в теории и практике гражданского права Германии возникают проблемы, связанные с применением к указанному институту положений наследственного и договорного права.

Ключевые слова: правовой режим, наследственный договор.

\section{GENERAL CHARACTERISTICS OF THE INHERITANCE CONTRACT IN GERMAN LAW}

\section{Shmakova Anastasia Sergeevna Churakova Ekaterina Nikolaevna}

\begin{abstract}
The article is devoted to the history and study of the peculiarities of the legal regime of the inheritance contract in civil law in Germany. The authors come to the conclusion that this institution has a mixed, hereditary-legal and contractual-legal character. In this regard, in the theory and practice of German civil law, there are problems associated with the application of the provisions of inheritance and contract law to this institution.
\end{abstract}

Key words: legal regime, inheritance contract.

История наследственного договора как особого института гражданского права начинается с постклассического периода римского частного права. В то время, помимо наследования в соответствии законом и завещанию, появилась возможность наследовать по договору, так называемым первым заветом pectum 
fiduciae (буквально: доверительный акт). Согласно данному договору, в семье, именно отец, определяет определенную часть своего имущества, по взаимному соглашению, то есть это его наследник в договорном порядке [1, с. 113]. Позже, в практике римских юристов, условия и предмет договора были изменены для обеспечения юридической силы, поскольку договор наследования расtе de successione Futura обычно не принимался во внимание. В связи с деятельностью римских юристов, законом об общей концепции договоров наследования был создан договор о наследовании, в силу которого вступил закон «О торжественной передаче имущества в случае смерти лицу, находящегося в состоянии естественного наследия» [2, с. 96].

Эта конструкция наследственного договора позже была принята средневековым германским законодательством, что по мнению Фердинанда Лассаля, устанавливило юридическую силу наследственных договоров в германском праве. На это указывают как средневековые, так и современные достопримечательности германского права.

С момента принятия в Германии Гражданского кодекса (далее - кодекс, ГГУ) идея наследования по договору распространилась за пределы страны. понимается заключение договора наследования. Этот кодекс регулирует все особенности наследования по договору, и регламентировал его смешанную наследсвенно-правовую и договорную природу. В соответствии с положениями пунктов 1 и 2 Гражданского кодекса ГГУ 1941 было установлено следующее определение наследственного договора: это взаимное соглашение, по которому одна сторона может назначить другую сторону (являющееся или не являющееся другим лицом в договоре) наследником всего своего имущества или его определенной части [3, с. 35].

Основная идея наследственного договора, закрепленные ГГУ, были в дальнейшем восприняты и закреплены правовыми системами других стран Европы - Австрией, Швейцарией, Англией и др. Позже наследственный договор появился в праве африканских и латиноамериканских стран. Специфическая модель наследственного договора утвердилась также в праве Англии и США.

В то же время эти страны (за исключением стран прецедентной правовой правящей семьи, где институты договора о наследовании существенно отличаются от европейской модели) дополнили модель Германского договора о наследовании и изменяли ее по мере необходимости времени и национальным особенностями правовой. Таким образом, наследственные договора наиболее 
популярны и распространены во многих развитых странах, включая Германию, Англию и Швейцарию. Так, в ФРГ наследственными договорами регулируется $35 \%$ всех наследственных отношений, в Англии - 64,8\%, в Швейцарии - 82\% [4, с. 549]. Приведенные выше данные свидетельствуют о том, что договор о наследовании, как основание наследования, используется не только наравне с традиционным завещанием, но и преобладает над ним. В связи с этим представляется целесообразным в данном исследовании уделить больше внимания анализу договоров о наследовании в гражданском праве Германии.

Как уже оговаривалось выше, исторически первым государством Европы, где возник институт наследственного договора, стала Германия, в цивилистической доктрине которой было сформулировано общее понятие наследственного договора Erbvertrag. Так, известный немецкий юрист Х. Грэйф, определяет наследственный договор как «распоряжение на случай смерти, которое составляется двумя или более лицами в форме договора, по которому наследодатель назначает своим наследником вторую сторону договора или третье лицьо» [5, с. 335].

В науке немецкого гражданского права существует понятие «соглашение между живыми в случае смерти», которое включает в себя договор о наследовании. По сути, это вещные сделки, юридические последствия которых возникают после смерти одной из сторон. В то же время, общие положения о сделках (а в случае договора о наследовании - общие положения договора) применяются к этому институту в отношении оснований для признания недействительными, расторжения и прекращения. Действительно, наследственный договор обладает свойствами классического договора. Например, пункт 3 параграфа 2298 ГГУ определяет возможность расторжения договора о наследовании, параграф 2283 - возможность его оспаривания до открытия наследства, параграф 2287 - возможность признания наследственного договора недействительным в случае злоупотребления правом. Следует обратить внимание на высказывание Е.Р. Путинцевой, которая отмечает, «суть договора о наследовании заключается не только в передаче имущества другому лицу (как, например, в договоре купли-продажи), но и в назначении наследников», что прямо изложено в параграфе 2273 ГГУ [6, с.1058]. Данное свойство договора о наследовании определяет его обязательства перед договаривающимися сторонами, исключая возможность одностороннего отказа от исполнения договора и существенно ограничивая возможность его расторжения. Кроме того, в ГУУ есть примечание о том, что расторжение 
договора о наследовании происходит в соответствии с правилами, предусмотренными для составления завещания (параграфы 2231-2233 Кодекса).

При этом, классическое завещание - является односторонним актом, в то время содержание наследственного договора предусматривает распоряжения на случай смерти как одной из сторон (одностороннее соглашение о наследовании), так и в случае смерти обеих сторон (двустороннее соглашение о наследовании). В этом случае, если каждая из сторон примет соглашение, они приобретают взаимосвязанный характер, в данном случае, недействительность одного соглашения о наследовании из распоряжений влечет недействительности всего соглашения о наследовании.

Выражение воли двух и более лиц в договоре о наследовании, обусловило невозможность отступления от условия этого соглашения, путем фиксирования воли, если оно противоречит ему, так как завещание является односторонним актом [7, с. 276]. Кроме того, пункт 1 параграфа 2289 Гражданского кодекса, при заключении соглашения о наследовании, предусмотрено юридическое право на прекращение любого распоряжения на случай смерти, должно быть осуществлено до заключения этого договора. Нередко заключаются «возмездные» соглашения о наследовании, согласно которому, одна сторона имеет право давать распоряжения на случай смерти (например, назначает другую сторону наследником), а другая сторона, дает встречное имущественное предоставление (например, обязуется выплачивать указанную сумму, до конца жизни наследодателя). Интерес состоит в том, что, в отличие от обычного договора о наследовании, имеющего «отложенный правовой эффект», «возмездный» наследственный договор «выступает основанием возникновений двух правоотношений: относительного правоотношения, возникающего с момента заключения договора между его сторонами, и абсолютного наследственного правоотношения, возникающего после открытия наследства».

В то же время, интерес представляет позиция Верховного суда Германии № 30/19 в постановлении от 05 октября 2019 года. Истец - наследодатель по наследственному договору, требовал расторжения соглашения о наследовании с другой стороной - наследником, отказавшимся выполнять свои обязательства по настоящему договору - осуществлять уход за наследодателем в течении всей его жизни. Ответчик иск не признал, ссылаясь на законодательство Германии, а котором регламентировано в нормах о наследственном договоре, что встречное предоставление со стороны наследника может носить только имущественный характер (но не личный), в связи с чем он не обязан выполнять указанное в 
договоре требования, так как оно противоречит ГГУ. Верховного Суда Германии отметил, что соглашение о наследовании - это возмездный договор и в связи с этим имеет смешанный характер и подчиняется как действию норм ГГУ о наследственном договоре, так и положениям о сделках между живыми. Исходя из этого, Верховный суд постановил, если наследник, установленный в соглашении о наследовании, обязалось предоставить любое встречное требование (даже носящий неимущественный характер), то он должен исполнить свою договорную обязанность. в договоре о праве на наследство субъект государственной налоговой службы определяет положения о договоре о праве на наследство и о сделках между наследодателями. В противном случае, договор расторгается на специальных основаниях, предусмотренных параграфом 2295 ГГУ, так и на общих снованиях расторжения договоров, указанных в параграфе 323 ГГУ [8, с. 996].

Исходя из вышеизложенного, основными отличиями между германским наследственным договором и традиционным гражданско-правовым договором, является закрепленная в законе цель его заключения, в случае противоречий, какой именно договор будет считаться недействительным, форма данного договора, а также предмет договора и основания его расторжения. В то же время, как отмечалось выше, наследственный договор также отличается от классических правил в случае смерти, поскольку он может быть двусторонним и иметь двусторонне обязывающий характер (не может быть изменен в одностороннем порядке по воле одной из сторон), а также приобретает обязательную силу с момента его заключения.

\section{Список литературы}

1. Michael E.O. Validity of testamentary contracts and promises: by wills. 2016. - C. 259.

2. Петров Е.Ю. (ред.) Основы наследственного права России, Германии, Франции. - М.: Статут, - 2015. - 271 с.

3. Пучков О.А., Пучков В.О. Наследственный договор как особый институт гражданского права иностранных государств: общая характеристика и проблемы правового режима - Правопорядок: история, теория, практика. - 2016. - № 3. - С. 34-39.

4. Эннекцерус Л. Курс германского гражданского права: Введение и общая часть. - М.: Иностр. лит., - 1950. - 483 с. 
5. Brox H., Walker W.-D. Erbrecht. 28 Aufl. - München: Vahlen, - 2018, $538 \mathrm{p}$.

6. Burandt W. et al. Erbrecht. Kommentar. 3 Aufl. - München: Beck, - 2019, 2050 p.

7. Frank R., Helms T. Erbrecht. 7 Aufl. - München: Beck, - 2018, - 383 p.

8. Süß R. Erbrecht in Europa. 3 Aufl. - Bonn: Zerber, - 2019, - 1526 p. 